\title{
Mitochondrial antigens and antibodies in primary biliary cirrhosis
}

\author{
Patrice Butler, Francesca Valle and Andrew K. Burroughs
}

Hepato-biliary and Liver Transplantation Unit, University Department of Medicine, Royal Free Hospital and School of Medicine, Pond Street, Hampstead, London NW3 2QG, UK

\section{Introduction}

Primary biliary cirrhosis (PBC) is considered to be an autoimmune chronic liver disease. It is characterized by progressive inflammatory destruction of intrahepatic bile ducts which results in cholestasis and which may progress to cirrhosis and liver failure. It is a disease which occurs in females in $90 \%$ of cases. The diagnosis is most commonly made in middle aged women who present with itching and usually with jaundice. However, less severe cases are being diagnosed because of cholestatic liver function tests or the presence of antimitochondrial antibodies (AMAs) in the serum. The latter are the most characteristic feature of PBC. ${ }^{1}$ These AMAs are non-organ- and nonspecies-specific and are of both the IgG and IgM classes. They were first detected in PBC patients in 1965 by Walker et al. ${ }^{2}$ by indirect immunofluorescence tests on cryostat sections. To date, 9 different AMA types (anti-M1 to anti-M9) have been defined, using immunofluorescence and complement fixation tests (CFTs), enzyme linked immunosorbent assay (ELISA) and Western blotting. ${ }^{3-5}$ Four of these AMAs, anti-M2, -M4, -M8 and -M9 are associated with PBC. The others anti-M1, -M3, -M5, -M6 and -M7 are mainly associated with non-hepatic disorders. ${ }^{6}$ The past 4 years have seen a great expansion in publications related to the immunology of PBC due to the identification of the major M2 antigens and the use of molecular biology techniques. These give good prospects for a better understanding of the pathogenesis of the disease.

\section{M2 - a family of autoantigens}

Approximately $95 \%$ of $\mathrm{PBC}$ sera react with a trypsin-sensitive inner mitochondrial membrane

Correspondence: A.K. Burroughs, F.R.C.P.

Received: 17 April 1991 antigen designated $\mathrm{M} 2 .^{7}$ Early experiments using chloroform extraction showed that the $\mathrm{M} 2$ antigen co-purified with the F1 part of the mitochondrial $\mathrm{H}^{+}$-ATPase, ${ }^{8,9}$ but further studies using immunoblotting techniques failed to demonstrate reactivity of anti-M2 antibodies with any of the major subunits of the F1-ATPase. ${ }^{10}$ M2 analysis by Western blotting has demonstrated at least 5 antigenic bands (M2a to M2e) with approximate molecular weights 80-68 kD (M2a), 64-60 kD (M2b), 56-50 kD (M2c), 48-43 kD (M2d) and $36 \mathrm{kD}$ (M2e). ${ }^{11,12}$ There is some confusion as to the exact molecular weights of eight of the M2 bands due to differences between laboratories with regare to species of mitochondria used, antigen preparation and techniques of detection. Recent identification of the antigens should allow pure preparations to be used in immunoblotting experiments. This would eliminate the apparent discrepancies.

In 1987 Gershwin et al. identified a cDNA clone isolated from a rat liver cDNA library which expressed the $70 \mathrm{kD}$ M2 autoantigen. ${ }^{13}$ This led to the identification of the 3 major M2 antigens as the E2 components (dihydrolipoamide acetyltransferases) of the three mitochondrial 2 oxo-acid dehydrogenase multienzyme complexes: pyruvate dehydrogenase complex (PDC), 2-oxoglutarate dehydrogenase complex (OGDC) and the branched chain 2-oxo-acid dehydrogenase complex (BCOADC). ${ }^{14,15} \mathrm{~A}$ fourth antigen was then identified which is designated protein X. ${ }^{16}$ This was found to possess cross-reactive AMA epitopes with the E2 of PDC. . $^{16,17}$

Each multienzyme complex consists of multiple copies of three enzymes E1, E2 and E3. The E2 component forms a central symmetrical core around which are arranged multiple copies of E1 and E3. The major immunodominant region on each of these enzymes and protein $\mathrm{X}$ is the lipoic acid binding site which possesses a covalently attached lysine residue. ${ }^{18,19} \mathrm{Up}$ to three lipoyl moieties can be present as a part of the functional 
site of the enzyme. Human PDC-E2 contains 3 autoreactive determinants, 2 cross-reactive lipoyl domains and an area surrounding the E1/E3 binding region, the dominant epitope being present on the inner lipoyl domain. ${ }^{20}$ The presence of a lipoyl residue is vital for antibody recognition. Fussey et al. have demonstrated that unlipoylated E2, where lysine was replaced by a glutamine residue was no longer recognized by $\mathrm{PBC}$ antibodies. However, if octanoic acid was added to the critical lysine residue, antibody binding properties were restored because octanoic acid can mimic the unique peptide cofactor conformation. ${ }^{21}$

Recently, Fussey et al. ${ }^{22}$ have shown that $41 \%$ of $\mathrm{PBC}$ sera react with the non-lipoic acid-containing E1 alpha component ( $41 \mathrm{kD})$ of mammalian PDC, and $7 \%$ react with the $\mathrm{E} 1$ beta component $(36 \mathrm{kD})$. Fregeau et al. ${ }^{23}$ have shown that $66 \%$ of PBC beta react with the $\mathrm{E} 1$ alpha component and $2 \%$ react with the $\mathrm{E} 1$ beta component. Interestingly, the autoantibody specific for E1 alpha (a non-lipoic acid-containing enzyme) was able to inhibit PDC complex activity. The other AMAs have also been shown to inhibit their respective enzyme complexes - this is not too surprising as the immunoepitopes are important functional sites. ${ }^{24,25}$

The specificity of antimitochondrial antibodies in 211 PBC patients has been examined: $209(99 \%)$ were found to have antibodies against one or more autoantigens, the majority $203(96 \%)$ having antibodies to PDC and protein X. ${ }^{16}$ Fregeau et al. ${ }^{26}$ have shown that $10 \%(19 / 188)$ of PBC sera reacted to OGDC-E2 when probed against bovine heart mitochondria. However, when these sera were probed against purified OGDC-E2 an additional 54 sera $(29 \%)$ exhibited weak reactivity. This implies that an increased sensitivity is obtained when pure enzyme preparations are used. Overall, this group demonstrated that $39 \%$ of $\mathrm{PBC}$ sera reacted with OGDC-E2. This is lower than the $72 \%$ of PBC sera that reacted with OGDC-E2 as described by Fussey et al. ${ }^{15}$ and is another source of heterogeneity of results in this field. Are the different prevalences of antibodies due to sampling of different populations or due to different techniques of identification?

Van de Water et al..$^{27}$ have developed an enzyme linked immunosorbent assay (ELISA) using recombinant cloned antigens to quantify specific antimitochondrial antibodies in patients with $P B C$. This method has also been successfully used by Heseltine $e t$ al. ${ }^{28}$ However, in contrast to the cloned antigens used by Gershwin et al. they used the purified PDH complex obtained through successive gel filtration steps. ELISA is a highly sensitive and quantitative method for detection of AMA. It should eventually substitute immunofluorescence as the standard method for detection of mitochondrial autoantibodies in clinical practice.

\section{Anti-M4, -M8 and -M9 autoantibodies}

The finding of anti-M4 antibody in PBC was originally thought to indicate an overlap disease between PBC and chronic active hepatitis as this 'mixed form' condition was usually associated with the presence of anti-M2 and anti-M4 AMA on immunofluorescence. ${ }^{29}$ Whilst some PBC patients exhibit both $\mathrm{M} 2$ and M4 reactivity on immunofluorescence, some sera may show only the M4 pattern. A study carried out using sera positive for AMA on immunofluorescence but negative when reacted with M2 rich preparations on immunoblots showed that these sera reacted with a single antigen (MW 50-52 kD) - M4. ${ }^{30}$ In this study, reactivity with the $52 \mathrm{kD}$ antigen alone was constant, irrespective of disease stage, whereas the occurrence of anti-M2 and anti-M4 in sera increased with disease progression. The M4 antigen is trypsin insensitive and probably located on the outer mitochondrial membrane.

Anti-M8 antibody is only found in association with anti-M2. However, not all anti-M2 patients have anti-M8. A serial study has shown that the presence of anti-M8 when detected with anti-M2 and anti-M4 may characterize a subgroup of patients with progressive disease activity. ${ }^{31}$

Anti-M9 antibody is predominantly present in patients with asymptomatic and early PBC. It can occur in patients who have been clinically and histologically defined as having $\mathrm{PBC}$ but who are M2-negative. Interestingly, it can also occur in healthy controls exposed to PBC, i.e. relatives and laboratory workers. When purified M9 antigen (isolated from rat liver mitochondria) is subjected to electrophoresis and Western blotting, anti-M9 antibodies detect 2 antigenic determinants at molecular weights of 98 and $59 \mathrm{kD}^{32}$

There is dispute as to whether the type and titre of mitochondrial antibodies have prognostic value in PBC. ${ }^{33}$ However, Weber et al. have recently suggested that AMA profiles are predictors of prognosis. They found that the presence of anti-M8 with anti-M2 (Profile II) and anti-M4 with anti-M8 and anti-M2 (Profile III) is associated with a more advanced histological stage at the time of diagnosis and a more progressive course than in patients with anti-M2 alone (Profile I). After following these patients for up to 16 years it was found that only $24 \%$ of patients with Profile I had reached stage III or IV (fibrosis or cirrhosis of the liver) while $75 \%$ of patients with Profile II or III had a progression to stage III or IV. ${ }^{31}$ Klein et al. have shown that AMA profiles determined at early stages of PBC differentiate between a benign and a progressive course of the disease ${ }^{34}$ This finding, if confirmed, should be of great importance in the design of therapeutic trials, clinical monitoring and decision making regarding liver transplantation. At present the M4, 
M8 and M9 (and M3, M5, M6 and M7) remain uncharacterized.

The role mitochondrial antibodies play, if any, in the pathogenesis of PBC is still unclear. However, Heseltine $e t$ al. have recently shown that the titre of immunoglobulin $G$ autoantibodies to purified PDC-E2 and X increases significantly not only with histological progression of disease but also with established prognostic 'markers' i.e. higher serum bilirubin and lower serum albumin levels. ${ }^{28}$

\section{Peptide specific and cross-reactive M2 autoantibodies}

As all of the M2 antigens identified so far except for $\mathrm{E} 1$ possess at least one lipoyl domain, it is possible that each of these antigens may possess cross reactive epitopes. Cross-reactivity between PDC$\mathrm{E} 2$ and protein $\mathrm{X}$ has been confirmed by several groups working in the field. However, there have been conflicting reports on the cross-reactivity of the other M2 antigens. Surh et al. ${ }^{16}$ have shown that AMA cross-reactivity is limited to PDC-E2 and protein $\mathrm{X}$, as reactivity with OGDC and BCOADC was not affected by absorption with recombinant PDC-E2. In addition, Fregeau et al. ${ }^{26}$ have demonstrated that affinity purified antisera from the OGDC-E2 did not react on immunoblot with any component enzymes of PDC or BCOADC. Fussey et $a l .{ }^{35}$ have demonstrated that neither PDC-E2 nor protein $\mathrm{X}$ antibodies recognize OGDC-E2, BCOADC-E2 or PDC-E1 alpha/beta. However, in 12 of 12 PBC sera, antibodies eluted from either OGDC-E2 or BCOADC-E2 showed complete cross-reactivity with each other. Eluted AMA from PDC-E1 alpha/beta showed complete specificity for each polypeptide.

In contrast, our group have demonstrated unequivocal cross-reactivity between each of the major M2 antigens using affinity purified antibodies from mitochondrial proteins immobilized on nitrocellulose blots. ${ }^{36}$ This has been independently confirmed by Fusconi et al..$^{37}$ using the same techniques. They have demonstrated that both cross-reactive and peptide specific antibodies are present in PBC sera. They have shown three epitopes to be present on both PDC-E2 and protein $\mathrm{X}$, two epitopes on the BCOADC-E2 and three on the OGDC-E2: one of these epitopes was common to all bands.

We have suggested that there are both peptidespecific and cross-reactive AMA. Thus, different sera may have different proportions of antibodies of these two kinds. Relative affinities of AMAs for antigens may be an important factor in explaining apparent discrepancies in results. One group has shown a considerable heterogeneity of relative affinities of AMA in PBC. ${ }^{38}$
The conformation of epitopes on the lipoic acid binding site may be another factor in determining their antigenicity. Our group have shown that neither lipoate nor lipoamide react with $\mathrm{PBC}$ sera using direct and competitive enzyme linked immunosorbent assays. ${ }^{36}$ Fussey et al. ${ }^{19}$ have shown that preincubation of PBC sera with $1 \mathrm{mM}$ lipoate, $1 \mathrm{mM}$-lipoamide alone or in combination failed to absorb out the reactivity of PBC sera against PDC-E2 in immunoblotting experiments. Surh et al. ${ }^{39}$ have demonstrated that a minimum of 75 amino acids is required to detect autoantibody binding on the inner lipoyl domain of PDH-E2, and that 93 amino acids are required for strong AMA activity. Because such a large region is required for reactivity, it is thought, and it is probable, that a conformational epitope is important in autoreactivity. Leung et al. ${ }^{40}$ have designed mutant structures to replace the lysine residue in the lipoyl domain. They used glutamine, a negatively charged amino acid; histidine, a positively charged amino acid; and tyrosine, an aromatic amino acid. In contrast to the findings by Fussey $e t$ al. ${ }^{21}$ they found that a variation in the charge distribution at the lipoyl domain of PDC-E2 and the removal of lipoic acid by the change of a single amino acid did not significantly alter antibody binding at the lipoyl domain, i.e. the reactivity is not influenced by the presence of lipoic acid. Theyo suggest that $\mathrm{PBC}$ autoantibodies are recognizing aspecific amino acid sequence and its associated secondary or even tertiary structure.

Injection of purified recombinant dihydrolipoamide acetyltransferase into animals generates mitochondrial autoantibodies, but their specificity is not the same as in PBC patients, as there is no cross-reactivity with protein $\mathrm{X}$, or the outer lipoyl domain and no enzyme inhibition in vitro. ${ }^{41,42}$

\section{Antimitochondrial activity with prokaryotes}

It is known that the AMAs of PBC patients react with certain bacterial proteins. Cross-reactivity has been demonstrated between PBC sera and a range of microrganisms, Paracoccus denitrificans, ${ }^{43} E$. coli, Klebsiella pneumoniae, ${ }^{36,44}$ Proteus mirabilis, Citrobacter freundii, Staphylococcus aureus ${ }^{36}$ and Enterobacteriaciae. ${ }^{45}$ This is hardly surprising considering that bacterial PDC-E2 exhibits a high degree of homology with its mammalian counterparts, particularly at the highly conserved region around the lysyl binding site for lipoate. E. coli PDC-E2 contains three lipoyl domains, ${ }^{46}$ reactivity being confined to the inner regions. However, there are differences in the organization of the transacetylase, with the mammalian E2 existing as a core of 60 copies in an icosahedral symmetry, and the bacterial one as 24 copies in an octahedral array. 
PBC sera have been shown not to react with bacterial PDC-E1. The protein sequence analysis of human E1 shows no similarity with any sequence deduced from $E$. coli PDC-E1. ${ }^{22}$

Reactivity of $\mathrm{PBC}$ serum with polypeptides from $E$. coli was initially described by LindenbornFotinos et al..$^{10}$ and confirmed by Frazer et al. ${ }^{47}$ by means of immunoblot techniques. Reactivity on immunoblots is with a $70-80 \mathrm{kD}$ and a $52 \mathrm{kD}$ membrane fraction. It has been shown that antibodies against both determinants can be absorbed with beef heart submitochondrial particles, showing that $E$. coli shares cross-reacting determinants with mitochondria. We have shown that by eluting antibodies from these bacterial bands on immunoblots and reacting them back with mitochondria unequivocal cross-reactivity can be obtained. ${ }^{36}$ Stemerowicz et al.$^{45}$ have demonstrated that AMA production can be induced in rabbits by intravenously injecting them with rough forms of laboratory strains of Salmonella minnesota. Rabbit antisera raised against Salmonella minnesota $\mathrm{Rb}$ and Rc mutants recognized the PBC specific M2 antigens $74 \mathrm{kD}$ and $52 \mathrm{kD}$. However, antisera against wild-type Enterobacteriaciae did not react with M2.

Fussey et $a l^{21}$ have characterized the main immunogenic region in $E$. coli. They have shown that, in addition to recognizing $E$. coli E2-PDC, PBC antibodies also recognize $E$. coli $\mathrm{E} 2 \mathrm{OGDC}$, the main immunogenic region lying within the lipoyl domains. The BCOADC is not present in $E$. coli.

\section{Bacteriuria and PBC}

We have found that women with PBC are much more susceptible to recurrent significant bacteriuria than women with other types of chronic liver disease. $^{48}$ In our population of PBC patients, significant bacteriuria defined a specific sub-group of PBC patients with an increased risk of death. ${ }^{49}$

In light of this we decided to look at a group of patients suffering from recurrent significant bacteriuria with no clinical or biochemical evidence of chronic liver disease and on long term prophylactic antibiotic treatment. We found that $69 \%$ of these patients exhibited weak AMA reactivity on immunoblots, reactivity with the $74 \mathrm{kD}$ M2 fraction being the most common. When antibody to the $74 \mathrm{kD}$ was affinity purified it was found to crossreact with bacterial membrane fractions. ${ }^{50,51}$

We have been studying the relationships between significant bacteriuria, $\mathrm{R}$ mutants and M2 antibodies in PBC. We have found a high percentage $(40 \%)$ of rough forms of bacteria in infected urine obtained from PBC and recurrent urinary tract infection patients with no evidence of liver disease ${ }^{52}$ but not in women with non-PBC chronic liver disease. Rough forms of bacteria have defective polysaccharide synthesis leading to an abnormal outer coat. Hopf et al ${ }^{53}$ have shown that $E$. coli $\mathrm{R}$ forms constituted an average of $5 \%$ (range $1-50 \%)$ of the total amount of $E$. coli present in the stool samples from 21/21 PBC patients. ${ }^{53}$ This is low compared to the percentage we found in infected urine of $\mathrm{PBC}$ patients considering that in the majority of cases organisms causing urinary infections originate in the gut. This implies that there might be 'selection' of the rough mutant bacteria causing urinary infections. Deposits of lipid A which is a component of the bacterial cell wall were found by Hopf et al. ${ }^{53}$ in the cytoplasm of hepatocytes in $11 / 21$ of the PBC patients mentioned above but not in the liver sections of patients with chronic viral hepatitis. ${ }^{53}$ These lipid A containing hepatocytes were located around the central veins and not the portal tracts. This would imply that bacteria did not arrive via the portal system from the gut but via the arterial blood supply. When one takes into account that many urinary tract infections in PBC are associated with the upper urinary tract, ${ }^{54}$ haematogenous spread to the liver is a possibility.

Thus we hypothesize that M2 autoantibodies may be an immune response to rough forms of urinary bacteria, as microbial peptides may become more easily exposed due to their defective outer coat and act as antigens. Perhaps the paracrystalline arrangement of the E2 core may render it especially antigenic as it resembles a viral structure. This hypothetical sequence of events may be specific to urinary infection, as $E$. coli antibodies are found very frequently in chronic liver disease, ${ }^{55}$ but AMA are specific to PBC.

\section{PBC - the autoimmune disease}

The chronic liver damage in PBC is thought to be mediated by $T$ lymphocytes infiltrating the biliary epithelium either by cytotoxic activity or by releasing lymphokines that attract bystander $\mathrm{T}$ cells. Major histocompatibility complex (MHC) class I antigens HLA A, B and C are cell surface glycoproteins normally found on all nucleated cells. MHC class II antigens HLA DP, DQ and DR are usually found on a limited number of cells including macrophages, B lymphocytes, dendritic cells and vascular endothelial cells: they are important in antigen presentation. MHC class II expression is a prerequisite of antigen recognition by class II restricted CD4 positive T lymphocytes. Normal bile duct epithelium possesses MHC class I but not class II antigens. However, several groups have now demonstrated MHC class II expression on bile duct epithelium in PBC. In 1984 Ballardini et al. ${ }^{56}$ 
showed MHC class II expression in 8/10 PBC liver biopsies. In 1986 Pisi et al.$^{57}$ demonstrated HLADR antigen expression in $50 \%$ of bile ducts in early PBC and in $100 \%$ in late stage PBC. Gores et al. ${ }^{58}$ carried out a study of 114 PBC patients and found that those possessing the HLA-DRw8 antigen were at an increased risk of death compared to those possessing the HLA-DR5 antigen.

However, almost all cells can be induced to express class II antigens by cytokines, in particular interferon gamma, ${ }^{59}$ which is also a trigger for intercellular adhesion molecule-1 (ICAM-1) which is essential for many immunological functions. ${ }^{60}$ MHC class II expression has also been shown in rejection following liver transplantation. In hepatic graft-versus-host disease the intrahepatic bile ducts express HLA-DR antigens after bone marrow transplantation. ${ }^{61,62}$ Focal HLA-DR expression on bile duct epithelium has also been reported in large bile duct obstruction and in liver tissue adjacent to metastatic carcinoma as well as in cases of intrahepatic cholestasis, granulomatous hepatitis, autoimmune hepatitis, cryptogenic cirrhosis and alcoholic hepatitis. ${ }^{63-65}$ Thus HLA II expression is cytokine mediated and this in turn can be due to a variety of causes.

The CD3 +, CD4 +, CD8 - T lymphocyte is the predominant cell type surrounding the portal tracts in late stage PBC. ${ }^{66,67}$ Other studies show that CD8 + T lymphocyte is predominant ${ }^{68-70}$ but one of the studies showed an increased tendency toward CD4 + in late stage disease. ${ }^{70}$ Even though $T$ cells are the predominant cell type infiltrating the portal tracts in PBC it is still not clear whether these cells are actually causing the damage.

In autoimmune diseases like PBC it is unknown how intracellular antigens (i.e. mitochondrial PDC-E2) present themselves to the immune system. Studies on surface expression of antigenicity have demonstrated that $\mathrm{PBC}$ sera can react at the surface of teased out hepatocytes and intact hepatoma cells. ${ }^{72}$ However, these studies have been criticized as it was possible that the cells studied did not retain their integrity, thus exposing intracellular components. ${ }^{73}$ Another possibility is that intracellular antigens may be released during natural cell death and turnover, enabling them to bind to MHC molecules and be presented on the surface of the cell (i.e. biliary epithelial cell or hepatocyte). CD4 + T lymphocytes can then recognize this MHC-antigen complex and can thus provide help for autoimmune B cells with a corresponding antigen activity. There is also evidence that MHC molecules may normally present selfpeptides in their binding site ${ }^{74}$ these peptides are probably intracellular proteins. It is not known if PDC-E2 or other mitochondrial antigens are exposed in this fashion. Other studies have shown that cytochrome $\mathbf{P}-450$ isoenzymes present in the cytoplasm are recognized by specific antibodies (anti-LKM 1 and 2) as some epitopes are localized on the outer surface ${ }^{75}$ these antibodies characterize specific subtypes of autoimmune chronic active hepatitis.

A further hypothesis is that $\mathrm{T}$ lymphocytes are stimulated by E3 components on bacterial cell membranes. These $T$ lymphocytes recognize crossreacting determinants on biliary epithelial cell (BEC) plasma membranes as these are thought to possess E3. Bile duct destruction ensues, E2 becomes exposed and in association with MHC II can then be recognized by CD4 + T lymphocytes. ${ }^{16}$

\section{Molecular mimicry and PBC}

We think antigenic mimicry between foreign and self antigen may be an important factor in the induction of M2 autoantibodies in PBC. Molecular mimicry has been indicated as a possible mechanism for autoimmunity in some diseases. In ankylosing spondylitis (AS) approximately $90 \%$ of patients are known to possess HLA B27. This HLA subtype cross-reacts with antigens found in Klebsiella which can be isolated in faecal cultures obtained from AS patients during active phases of disease. ${ }^{76}$ In reactive arthritis, Salmonella antigens? (O-polysaccharide of bacterial lipopolysaccharide have been found in joint material from patients with Salmonella-triggered reactive arthritis. In ar animal model, the lipid A part of LPS is responsible for inducing arthritis. Processed LPS is very effective at stimulating lymphocytes which in turn leads to the production of cytokines and hence inflammation. ${ }^{77}$ We hypothesize that cytokine induction and MHC II expression in PBC may be a response to infections with $\mathbf{R}$ forms of bacteria. In Yersinia-triggered reactive arthritis, non-viable structures of Yersinia enterocolitica $0: 3$ have been shown at the site of inflammation within mononuclear cells in the synovial membrane of $80 \%$ of patients. ${ }^{78}$ Specific anti-Proteus antibodies have been shown to be present in active rheumatoid arthritis. Anti-HLA-DR4 tissue typing sera have been shown to bind to Proteus microrganisms. ${ }^{79}$

In myasthenia gravis the circulating antibodies directed against the nicotinic acetylcholine receptor are pathogenetic. Monoclonal antibodies raised against this receptor were found to bind to outer membrane proteins from $E$. coli, Klebsiella pneumoniae and Proteus vulgaris. ${ }^{80}$ Recently it has been shown that sera from PBC patients possess antibodies against the alpha and probably the beta and gamma subunits of nicotinic acetylcholine receptor $^{81,82}$ yet no patient had any clinical or electromyographic evidence of myasthenia gravis. This would indicate that 'host response' is important in the generation of autoimmune disease. In PBC, 
mitochondrial antibodies could be pathogenetic if the host immune environment facilitates this. The recent great strides in our knowledge of the mitochondrial antigens outlined in this review should facilitate study of the interactions between antigens and lymphocytes, and hopefully map out the pathogenesis and progression of $\mathrm{PBC}$, deter- mining whether anti-mitochondrial antibodies cause disease in PBC.

Note added in proof: Klein, R. and Berg, P.A. have recently identified the epitope reacting with anti-M9 as to be part of glycogen phosphorylase (Clin Exp Immunol 1990, 81: 65-71) and anti-M4 reacting with sulphite oxidase (Clin Exp Immunol 1991, 84: 445-448).

\section{References}

1. Berg, P., Doniach, D. \& Roitt, I.M. Mitochondrial antibodies in PBC. I Localization of the antigen to mitochondrial membranes. J Exp Med 1967, 126: 277-290.

2. Walker, J.G., Doniach, D., Roitt, I.M. \& Sherlock, S. Serological tests in diagnosis of PBC. Lancet 1965, i: 827-831.

3. Baum, H. \& Berg, P.A. The complex nature of mitochondrial antibodies and their relation to primary biliary cirrhosis. Semin Liver Dis 1981, 1: 309-321.

4. Meek, F., Khoury, E.L., Doniach, D. \& Baum, H. Mitochondrial antibodies in chronic liver disease and connective tissue disorders: further characterization of the autoantigen. Clin Exp Immunol 1980, 41: 43-54.

5. Berg, P.A., Klein, R. \& Lindenborn-Fotinos, J. Antimitochondrial antibodies in primary biliary cirrhosis. $J$ Hepatol 1986, 2: 123-131.

6 Berg, P.A. \& Klein, R. Heterogeneity of anti-mitochondrial antibodies. Semin Liver Dis 1989, 9: 103-115.

7. Kaplan, M.M. Primary biliary cirrhosis. N Engl J Med 1987 , 316: 521-528.

8. Lindenborn-Fotinos, J., Sayers, T.J. \& Berg, P.A. Mitochondrial antibodies in primary biliary cirrhosis. VI. Association of the complement fixing antigen with a component of the mitochondrial ATPase activity. J Bioenerg Biomemb 1981, 13: $255-267$

9. Sayers, T.J., Leoutsakos, A., Berg, P.A. \& Baum, H. Antimitochondrial in primary biliary cirrhosis. I. Separation of the PBC antigen activity from mitochondrial ATPase activity. J. Bioenerg Biomemb 1981, 13: 255-267.

10. Lindenborn-Fotinos, J., Baum, H. \& Berg, P.A. Mitochondrial antibodies in primary biliary cirrhosis: species and non-species specific determinants of M2 antigen. Hepatology 1985, 5: 763-769.

11. Berg, P.A. \& Klein, R. Immunology of primary biliary cirrhosis. Ballières Clin Gastroenterol 1987, 1: 675-706.

12. Berg, P.A. \& Klein, R. Molecular determination of the PBC specific M2 antigen. Hepatology 1988, 8: 200-201 (correspondence).

13. Gershwin, M.E., Mackay, I.R., Surgess, A. \& Coppel, R.L Identification and specificity of a cDNA encoding the $70 \mathrm{kD}$ mitochondrial antigen recognized in primary biliary cirrhosis. J Immunol 1987, 138: 3525-3531.

14. Yeaman, S.J., Danner, D.J., Mutimer, S.P., Fussey, S.P.M., James, O.F.W. \& Bassendine, M.F. Primary biliary cirrhosis: identification of two major M2 mitochondrial autoantigens. Lancet 1988, i: 1067-1070.

15. Fussey, S.P.M., Guest, J.R., James, O.F.W., Bassendine, M.R. \& Yeaman, S.J. Identification and analysis of the major M2 autoantigens in primary biliary cirrhosis. Proc Natl Acad Sci USA 1988, 85: 8654-8658.

16. Surh, C.D., Roche, T.E., Danner, D.J. et al. Antimitochondrial autoantibodies in primary biliary cirrhosis recognize cross-reactive epitope(s) on protein $\mathrm{X}$ and dihydrolipoamide acetyltransferase of pyruvate dehydrogenase complex. Hepatology 1989, 10: 127-133.

17. Multimer, D.J., Fussey, S.P.M., Yeaman, S.J., Kelly, P.J., James, O.F.W. \& Bassendine, M.F. Frequency of IgG and IgM autoantibodies to four specific M2 autoantigens in primary biliary cirrhosis. Hepatology 1989, 10: 403-407.
18. Van de Water, J. Gershwin, M.E., Leung, P., Ansari, A. \& Coppel, R.L. The autoepitope of the $74 \mathrm{kD}$ mitochondrial antigen in primary biliary cirrhosis corresponds to the functional site of dihydrolipoamide acetyltransferase. $J$ Exp Med 1988, 167: 1791-1799.

19. Fussey, S.P.M., Bassendine, M.F., James, O.F.W. \& Yeaman, S.J. Characterization of the reactivity of autoantibodies in primary biliary cirrhosis. FEBS Lett 1989, 246: 49-53.

20. Coppel, R.L., McNeilage, C.D. Surh, J. et al. Primary structure of the human M2 mitochondrial autoantigen of primary biliary cirrhosis: dihydrolipoamide acetyltransferase. Proc Natl Acad Sci USA, 1988, 85: 7317-7321.

21. Fussey, S.P.M., Ali, S.T., Guest, J.R., James, O.F.W., Bassendine, M.F. \& Yeaman, S.J. Reactivity of primary biliary cirrhosis sera with $E$. coli dihydrolipoamide acetyl transferase (E2p): characterisation of the main immunogenic region. Proc Natl Acad Sci 1990, 87: 3987-3991.

22. Fussey, .P.M., Bassendine, M.F., Fittes, D., Turner, I.B., James, O.F.W. \& Yeaman, S.J. The E1 alpha and beta subpyruvate dehydrogenase complex are M2 ' $d$ ' and M2 'e' autoantigens in primary biliary cirrhosis. Clin Sci 1989, 77: 365-268.

23. Fregeau, D.R., Roche, T.E., Davis, P.A., Coppel, R. \& Gershwin, M.E. Inhibition of pyruvate dehydrogenase complex activity by autoantibodies specific for E1, a non lipoic acid containing mitochondrial enzyme. J Immunol 1990, 144: $1671-1676$.

24. Van de Water, J., Fregeau, D.R., Davis, P.A. et al. Autoantibodies of primary biliary cirrhosis recognize dihydrolipoamide acetyltransferase and inhibit enzyme function. $J$ Immunol 1988, 141: 2321-2324.

25. Fregeau, D.R., Davis, P.A., Danner, D.J. et al. Antimitochondrial antibodies of primary biliary cirrhosis recognize dihydrolipoamide acetyltransferase and inhibit enzyme function of the branched chain alpha ketoacid dehydrogenase complex. J Immunol 1989, 142: 3815-3820.

26. Fregeau, D.E., Prindiville, T. Coppel, R.L., Kaplan, M., Rolland Dickson, E. \& Gershwin, M.E. Inhibition of alphaketoglutarate dehydrogenase activity by a distinct population of autoantibodies recognizing dihydrolipoamide succinyltransferase in primary biliary cirrhosis. Hepatology 1990, 11: 975-981.

27. Van de Water, J., Cooper, A., Surh, C. et al. Detection of autoantibodies to recombinant mitochondrial proteins in patients with PBC. $N$ Engl J Med 1989, 330: 1377-1380.

28. Heseltine, L., Turner, I.B., Fussey, S.P.M. et al. Primary biliary cirrhosis: quantitation of autoantibodies to purified mitochondrial enzymes and correlation with disease progression. Gastroenterology 1990, 99: 1786-1792.

29. Berg, P.A., Wiedmann, K.H., Sayers, T. \& Kloppel, G. Serological classification of chronic cholestatic liver disease by use of 2 different types of anti-mitochondrial antibodies. Lancet 1980, ii: $1329-1332$.

30. Fusconi, M., Ghadiminejad, I., Bianchi, F.B., Baum, H., Bottazzo, G.F. \& Pisi, E. Heterogeneity of antimitochondrial antibodies of PBC with the M2-M4 pattern by immunofluorescence as described by Western immunoblotting and enzyme linked immunosorbent assay. Gut 1988, 29: 440-447. 
31. Weber, P., Brenner, J., Stechemesser, E. et al. Characterisation and clinical relevance of a new complement-fixing antibody -Anti-M8-in patients with primary biliary cirrhosis. Hepatology 1986, 6: 553-559.

32. Klein, R., Kloppel, G., Fischer, R. et al. The antimitochondrial antibody anti-M9. A marker for the diagnosis of early PBC. J Hepatol 1988, 6: 299-306.

33. Smith, N. \& Boyer, J.L. Are antimitochondrial antibodies of prognostic value in PBC? Hepatology 1986, 6: 739-741.

34. Klein, R., Kloppel, G., Garbe, W., Fintelmann, V. \& Berg, P.A. Antimitochondrial antibody profiles determined at early stages of PBC differentiate between a benign and a progressive course of the disease. J Hepatol 1991, 12: 21-27.

35. Fussey, S.P.M., Yeaman, S.J., James, O.F.W. \& Bassendine, M.F. Peptide-specific and cross-reacting autoantibodies to mammalian 'M2' antigens in PBC sera. Hepatology 1990, 12: 394 (abstr).

36. Flannery, G.R., Burroughs, A.K., Butler, P. et al. Antimitochondrial antibodies in primary biliary cirrhosis recognize both specific peptides and shared epitopes of the M2 family of antigens. Hepatology 1989, 10: 370-374.

37. Fusconi, M., Baum, H., Caselli, A. et al. Distribution of peptide-specific and cross-reactive epitopes in proteins reacting with antimitochondrial antibodies of primary biliary cirrhosis. J Hepatol 1990, 11: S23 (abstr).

38. Robertson, C.A., Coppel, R.L., Prindiville, T. et al. The relative affinity of recombinant dihydrolipoamide transacetylase for autoantibodies in primary biliary cirrhosis. Hepatology 1990, 11: 717-722.

39. Surh, C.D., Coppel, R.\& Gershwin, M.E. Structural requirement for autoreactivity on human PDH-E2 the major autoantigen of PBC-Implication for a conformational autoepitope. J Immunol 1990, 144: 3367-3374.

40a Leung, P.S.C., Iwayama, T., Coppel, R. \& Gershwin, M.E. Site directed mutagenesis of lysine within immunodominant autoepitopes of PDC-E2. Hepatology 1990, 12: 1321-1328.

40b Leung, P.S.G. \& Gershwin, M.E. The molecular structure of autoantigens. Curr Op Immunol 1990, 2: 567-575.

41. Krams, S.M., Surh, C.D., Coppel, R.L. Ansari, A., Reubner, B. \& Gershwin, M.E. Immunization of experimental animals with dihydrolipoamide acetyltransferase as a purified recombinant polypeptide generates mitochondrial autoantibodies but not primary biliary cirrhosis. Hepatology 1989, 9: 411-416.

42. Surh, C.D., Ansari, A.-A. \& Gershwin, M.E. Comparative epitope mapping of murine monoclonal and human autoantibodies to human PDH-E2 the major mitochondrial autoantigen of primary biliary cirrhosis. J Immunol 1990, 144: $2647-2652$.

43. Sayers, T. \& Baum, H. Possible cross-reactivity of human antimitochondrial antibodies in membrane vesicles of Paracoccus denitrificans. Biochem Soc Trans 1976, 4: 138-139.

44. Baum, H. \& Palmer, C. The PBC-specific antigen. Mol Aspects Med 1985, 8: 201-236.

45. Stemerowicz, R., Hopf, U., Moller, B. et al. Are antimitochondrial antibodies in primary biliary cirrhosis induced by $\mathrm{r}$ (rough)-mutants of enterobacteriaciae? Lancet 1988, ii: $1166-1170$.

46. Stephens, P.E., Darlison, M.G., Lewis, H.M. \& Guest, J.R. The pyruvate dehydrogenase complex of Escherichia coli K12. Nucleotide sequence encoding the dihyrolipoamide acetyltransferase component. Eur J Biochem 1983, 133: 481-489.

47. Frazer, I.H., Mackay, I.R., Jordan, T.W., Whittingham, S. \& Marzuki, S. Reactivity of antimitochondrial autoantibodies in PBC: definition of 2 novel mitochondrial polypeptide autoantigens. J Immunol 1985, 3: 1739-1745.

48. Burroughs, A.K., Rosenstein, I.J., Epstein, O., Hamiltonmiller, J.M.T., Brumfitt, W. \& Sherlock, S. Bacteriuria and primary biliary cirrhosis. Gut 1984, 25: 133-137.

49. Morreale, M., Tsirigotis, M., Hughes, M.D., Brumfitt, W., McIntyre, N. \& Burroughs, A.K. Significant bacteriuria has prognostic significance in primary biliary cirrhosis. $J$ Hepatol 1989, 9: $149-158$
50. Burroughs, A.K., Butler, P., Brumfitt, W. \& Baum, H. Mitochondrial M2 autoantigens and PBC. Lancet 1989, i: 447-448 (correspondence).

51. Burroughs, A.K., Butler, P., Brown, D., Brumfitt, W., Hamilton-Miller, J.M.T. \& Baum, H. Specific reactivity of a mitochondrial antibody in women with recurrent urinary tract infection against the $\mathrm{PBC}$ specific $70 \mathrm{kD}$ mitochondrial (M2) autoantigen, demonstrated by immunopurification. $J$ Hepatol 1989, 9: S130 (abstr).

52. Burroughs, A.K., Butler, P., Valle, F. et al. M2 antibodies and Rough (R) mutants in urine of 'normal' women with recurrent bacteriuria, and in women with PBC. J Hepatol 1990, 11: S13 (abstr).

53. Hopf, U., Stemerowicz, R., Rodloff, A. et al. Relation between Escherichia coli $\mathbf{R}$ (rough) - forms in gut, lipid $\mathbf{A}$ in liver, and primary biliary cirrhosis. Lancet 1989, ii: 1419-1421.

54. Rosenstein, I.J.M. \& Burroughs, A.K. Bacteriuria and primary biliary cirrhosis. In: Asscher, A.W. \& Brumfitt, W. (eds) Microbial Diseases in Nephrology. John Wiley \& Sons, Bath, 1986, pp. 125-135.

55. Simjee, A., Hamilton-Miller, J.M.T., Thomas, H.C. et al. Antibodies to Escherichia coli in chronic liver disease. Gut 1975, 16: 871-875.

56. Ballardini, G., Bianchi, F.B., Doniach, D., Mirakian, R., Pisi, E. \& Bottazzo, G.F. Aberrant expression of HLA-DR antigens on bile duct epithelium in primary biliary cirrhosis: relevance to pathogenesis. Lancet 1984, ii, 1009-1013.

57. Pisi, E., Bianchi, F.B., Ballardini, G., Cassani, F. \& Bottazzo, G.F. New immunopathologic features in primary biliary cirrhosis. Front Gastrointest Res 1986, 9: 132-142.

58. Gores, G.J., Moore, S.B., Fisher, L.D., Powell, F.C. \& Dickson, F.R. Primary biliary cirrhosis: associations with II major histocompatibility complex antigen. Hepatology 1987 7: 889-892.

59. Franco, A., Barnaba, V., Natali, P., Balsano, C., Musca, A. Balsano, F. Expression of class I and class II major hist 5 compatibility complex antigens on human hepatocyteso Hepatology 1988, 8: 449-454.

60. Volpes, R., Sing-Hiem, Y., Joost, J., Van de Oord, J., Acsq, G. \& Desmet, V.J. Induction of intracellular adhesion molecule - I (ICAM-I) on HEPG 2 cells: influence of cytokines and HBV-DNA transfection. Hepatology 1990, 12: 336 (Abstr).

61. Dilly, D. \& Sloane, J.P. An immunohistological study of human hepatic graft-versus-host disease. Clin Exp Immunol 1985, 62: 545-553.

62. Miglio, F., Pignatelli, M., Mazzeo, V. et al. Expression of MHC class II antigens on bile duct epithelia in patients with hepatic graft-versus-host disease after bone marrow transplantation. J Hepatol 1987, 5: 182-189.

63. Barbatis, C., Kelly, P., Greveson, J., Heryet, A. \& O'D McGee, J. Immunocytochemical analysis of HLA class II (DR) antigens in liver disease in man. J Clin Pathol 1987, 40: 879-884.

64. Spengler, U., Pape, G.R., Hoffmann, R.M. et al. Differential expression of MHC class II subregion products on bile duct epithelial cells and hepatocytes in patients with primary biliary cirrhosis. Hepatology 1988, 8: 459-462.

65. Chapman, R.W., Kelly, P., Heryat, A. et al. Expression of HLA-DR antigens on bile duct epithelia in primary sclerosing cholangitis. Gut 1988, 29: 422-427.

66. Lobo-Yeo, A., Alviggi, L., Mieli-Vargani, G., Portmann, B., Mowat, A.P. \& Vergani, D. Preferential activation of helper/ inducer $\mathrm{T}$ lymphocytes in autoimmune chronic active hepatitis. Clin Exp Immunol 1987, 67: 95- 104.

67. Krams, S.M., Van de Water, J., Coppel, R.L. et al. Analysis of hepatic $\mathrm{T}$ lymphocyte and immunoglobulin deposits in patients with primary biliary cirrhosis. Hepatology 1990, 12: 306-313.

68. Yamada, G., Hyodo, I., Tobe, K. et al. Ultrastructural immunocytochemical analysis of lymphocytes infiltrating bile duct epithelia in primary biliary cirrhosis. Hepatolog 1986, 6: $385-391$. 
69. Vento, S., O'Brien, C.J., McFarlane, B.M., McFarlane, I.G. Eddlestone, A. \& Williams, R. T-lymphocyte sensitization to hepatocyte antigens in autoimmune chronic active hepatitis and primary biliary cirrhosis. Gastroenterology 1984, 87: 763-769.

70. Hoffmann, R.M., Paper, G.R., Spengler, U. et al. Clonal analysis of liver-derived T cells of patients with PBC. Clin Exp Immunol 1987, 67: 95-104.

71. Meuer, S.C., Moebius, U., Manns, M. et al. Clonal analysis of human $\mathrm{T}$ lymphocyte infiltrating the liver in chronic active hepatitis B and primary biliary cirrhosis. Eur J Immunol 1988, 18: $1447-1452$.

72. Ghadiminejed, I. \& Baum, H. Evidence for the cell-surface localization of antigens cross-reacting with the 'mitochondrial antibodies' of primary biliary cirrhosis. Hepatology 1987 , 7: $743-750$.

73. Ghadiminejed, I. \& Baum, H. Hepatology 1988, 8: 706-707 (correspondence).

74. Bjorkman, P.J., Saper, M.A., Samraoudi, B., Bennett, W.S., Strominger, J.L. \& Wiley, C.D. The foreign antigen binding site and $\mathrm{T}$ cell recognition regions of class I histocompatibility antigens. Nature 1987, 329: 512-518.

75. Loeper, J., Descatoire, V., Maurice, M. et al. Presence of cytochrome P-450 on human hepatocyte plasma membrane. Recognition of several autoantibodies. Hepatology 1990, 12: 287 (abstr).
76. Ebringer, A. The relationship between Klebsiella infection and ankylosing spondylitis. Baillière's Clinical Rheumatology 1989, 3: 321-338.

77. Granfers, K., Jalkanen, S., Lindberg, A.A. et al. Salmonella lipopolysaccharide in synovial cells from patients with reactive arthritis. Lancet 1990, 335: 685-688.

78. Marilahti-Palo, R., Soderstron, K.-O., Lahesmaa-Rantala, R., Granfors, K. \& Toiranan, A. Bacterial antigens in synovial biopsy specimens in Yersinia triggered reactive arthritis. Ann Rheum Dis 1991, 50: 87-90.

79. Ebringer, A., Khalafpour, S. \& Wilson, C. Rheumatoid arthritis and Proteus: a possible aetiological association. Rheumatol Int 1989, 9: 223-228.

80. Stefansson, K., Dieperink, M.E., Richman, D.P., Gomez, C.M. \& Marton, L.S. Sharing of antigenic determinants between the nicotinic acetylcholine receptor and proteins in E. coli, Proteus vulgaris and Klebsiella pneumoniae. $N$ Engl J Med 1985, 312: 221-225.

81. Kyriatsoulis, A., Manns, M., Gerken, G. et al. Immunochemical characterization of anti-acetylcholine receptor antibodies in primary biliary cirrhosis. J Hepatol 1988, 6: 283-290.

82. Lefvert, A.K. \& Holm, G. Characterization of acetylcholine receptor antibodies in a patient with primary biliary cirrhosis. Acta Neurol Scand 1989, 80: 255-258. 